\title{
Prediction of Energy Absorption Capability in Fiber Reinforced Self-Compacting Concrete Containing Nano-Silica Particles using artificial neural network
}

\begin{abstract}
The main objective of the present work is to utilize feedforward multi-layer perceptron (MLP) type of artificial neural networks (ANN) to find the combined effect of nano-silica and different fibers (steel, polypropylene, glass) on the toughness, flexural strength and fracture energy of concrete is evaluated. For this purpose, 40 mix plot including 4 series $\mathrm{A}$ and $\mathrm{B}$ and $\mathrm{C}$ and $\mathrm{D}$, which contain, respectively, $0,2,4$ and $6 \%$ weight of cement, nano-silica particles were used as a substitute for cement. Each of series includes three types of fibers (metal: $0.2,0.3$ and $0.5 \%$ volume and polypropylene: $0.1,0.15$ and $0.2 \%$ volume and glass 0.15 and 0.2 and $0.3 \%$ by volume) were tested.

The obtained results from the experimental data are used to train the MLP type artificial neural network. The Results of this study show that fibers conjugate presence and optimal percent of nano-silica improved toughness, flexural strength and fracture energy of concrete of Self-compacting concrete (SCC). Results of this study show that fibers conjugate presence and optimal percent of nano-silica improved toughness, toughness, fracture energy and flexural strength of SCC.
\end{abstract}

\section{Keywords}

Fiber, Self-compacting concrete, Nano-silica, mechanical properties, artificial neural network.
Hamid Reza Tavakoli *a

Omid Lotfi Omran ${ }^{\text {b }}$

Saman Soleimani Kutanaeic

Masoud Falahtabar shiade ${ }^{\mathbf{d}}$

${ }^{a}$ Assistant Professor.Department of Civil Engineering, Babol University of Technology, Babol, IRAN, P.O.Box 484. E-mail: tavakoli@nit.ac.ir

${ }^{\mathrm{b}}$ Department of Civil Engineering; Guilan University, Rasht, Iran. E-mail:

Omid_saze_civil@yahoo.com

${ }^{ }$Department of Civil Engineering, Qaemshahr Branch, Islamic Azad University, Qaemshahr, Iran.

E-mail: samansoleimani16@yahoo .com

d Department of Civil Engineering,

Babol University of Technology, Babol, IRAN, P.O.Box 484.

E-mail:m falah tsh@yahoo.com

* Corresponding author. Tel.: +98 111 3231703.

\section{INTRODUCTION}

Self-compacting concrete (SCC) was first developed to improve durability stability of concrete structures in Japan in 1988 (Ozawa et al., 1996). According to the theory, SCC is a highly flowable and coherent concrete that is able to consolidate under its own weight without any vibration. In addition, it is able to maintain its uniformity after concrete filling and to fill the congested reinforced concrete structures (Ouchi et al., 1996; Nehdi et al., 2003; Khayat, 1999; Saffiuddin et al., 2011). Although steel bars are centrally placed in concrete and compensate the weakness to high extent, they are expensive and cannot be applicable in some areas such as surface of canals, airports overlays, etc. During the last decades string fibers have been used in concrete to solve the problem (Romualdi and Batson, 1963; Romualdi and Mandel, 1964). Rupture of concrete drastically depends on crack formation due to loading or environmental impacts. Continuous loading causes the cracks to propagate throughout the body of concrete (Soroushian, 1986). Using different reinforcing fibers in concrete to make Fiber Reinforced Concrete (FRC) is an effective method in preventing crack propagation and compensating shrinkage induced by low tensile strength [Seung et al., 2012]. Pres- 
ence Of fibers in concrete not only improve some mechanical properties such as resistance to crack creation and growth, strength and resistance to impact, but will also increase the ductility and energy required for fracture of concrete (Shah et al., 1995). The most important properties of fiber concrete are energy absorption, formability and resistance against strikes, Energy absorbing properties and sufferance of concrete can desirably reduce the risk of failure of concrete structures, especially in areas where concrete structures are under seismic and frequent loads.

Studies show that addition of different fibers does not fundamentally change the behavior of the concrete prior to its maximum stress while it greatly improves the concrete post-cracking behavior. This method positively influences other properties of the concrete including toughness, fracture energy and flexural strength. Energy absorption and strengthening of concrete can efficiently reduce the rupture risk in concrete structures, especially under alternative and vibrating loads. Therefore, when FRC is subjected to impact loading, cracks occurrence in matrix is much faster than the rupture occurrence in fibers. When cracks occur in the matrix, one of the followings might happen to the composite:

(A)Rupture might happen to the composite immediately after crack appearance in the matrix.

(B)Under lighter loads, the composite might still bear the load and continue deformation; this is the case when steel fibers are used in low to medium volume. In this condition, after cracking, strength is first provided when fibers are pulled out of the cracks and then continue when they are deformed. (C)After crack occurrence in matrix, the composite might be able to bear tensile stress and more deformation. This condition happens when fibers are used in medium to large amount. It should be noticed that this happens only when pull-out strength of fibers is more than the existing load at the moment of appearance of the first crack. This is because of sudden transfer of entire load to the fibers at the occurrence. When the load is increased, being stuck to the contact area, fibers transfer the extra stress to the matrix.

It is clear that FRC in (A), is not ductile and the highest level of ductility occurs in FRC in (C). To achieve the highest level of ductility in FRC, fiber-matrix interface should be reinforced.

More reports from measurement of toughness are the indices without foundation energy dimension, particularly laboratory applications of such indices with the introduction of toughness index ACI (ACI 544, 1988) based on Henegar work (Henegar, 1978) was started. ACI 544 express toughness index is ratio of energy required for deformation $1 / 9 \mathrm{~mm}$ fiber reinforced beam to energy required for creating first crack. One of the problems of this approach is determining reliable value of the location of the first crack, and also $1 / 9$ is an arbitrary value. In fact, range of deformation must be defined based on service level requirements. Of course, the ACI in new edition of itself has used toughness index of it that is defined as ratio of fibrous concrete absorbed energy to conventional concrete absorbed energy.

Japan's Concrete Institute JCI (JCI, 1984) define toughness index for a beam with a standard size, area under curve (load- deformation) to range (L/150). standards from Belgian (IBN, 1992), Germany (DBV, 1992), RILEM (RILEM, 1984) and Spain (AENOR, 1989) also suggest a similar trend and test. Energy absorption capacity, defined as the amount of absorbed energy in per basal area unit of sample in a certain deformation. Since in fibrous concrete obtaining first crack energy is not clearly identified and in ASTM C 1018 clearly don't evaluated. Therefore in order of more a logical comparison, area under the curve (load - displacement) to the final deformation is considered as the toughness of concrete.

One of the most important parameters in the study of concrete behavior, especially after reaching the peak load, is Energy required for creating crack the concrete unit level that fracture energy (GF) said (Gue et al., 1999). Direct method for determining fracture energy is the direct tensile tests (Bazant and Panas, 1997). Although some researchers have used this approach to determine the GF, it has many problems for concrete (Navalurkar et al., 1999; Elices et al., 2002). Other strategies have been proposed to determine the fracture energy that needs easier testes. Among them, we can mention two-parameter method of King (Jenq and Shah, 1985), Kazemi and Bezant 
size effect method (Bazant and Kazemi, 1990) and Hylrbrg's work method (RILEM, 1988). In the recent method, that mainly in the paper is used to determine the fracture energy, from the forcedisplacement curve of concrete beams in three-point bending test with displacement control to specimens complete failure is used. It is important to note that the method with modifications is recommended by RILEM - TC50 (The European Guideline for self compacting concrete specification, 2005).

In practical terms, artificial neural networks are essentially computer programs that can automatically find non-linear relationships and patterns in data without any pre-defined model form or domain knowledge. In recent years, artificial neural networks have been used to predicting the concrete properties (Flood et al., 2001; Pannir et al., 2009; Perera et al., 2010; Yang et al., 2008; Guang and Zong, 2000; Goh ATC, 1995; Sand and Saka, 2001; Jamal et al., 2007; Arslan et al., 2009; Arslan et al., 2007) from a literature study it could be find that there is no investigation on the combined effects of fibers and Nano silica on the Mechanical Properties of Self- Compacting Concrete using artificial neural network.

In this research, the combined effect of nano-silica particles and fibers type (steel, polypropylene and glass) on toughness, fracture energy and flexural strength of SCC were evaluated.For this purpose, forty mixtures in $\mathrm{A}, \mathrm{B}, \mathrm{C}$ and $\mathrm{D}$ series representing $0,2,4$ and 6 percent of Nano-silica particles replacing cement content were cast. Each series involved three different fiber type and content, $0.2,0.3$ and $0.5 \%$ volume for steel fiber, $0.1,0.15$ and $0.2 \%$ of volume for polypropylene fiber and finally $0.15,0.2$ and $0.3 \%$ of volume for glass fiber. The obtained results from the experimental data are used to train the MLP type artificial neural network. To train the present MLP-ANN the nano and fiber percent as the inputs and toughness, fracture energy and flexural strength as the outputs of the network are used. The trained network is used to predict the effect of various parameters on the desired output.

\section{Material properties and experimental setup}

\subsection{Material}

To carry out the experimental investigation, an amorphous nano-silica (nano-SiO2,Meyco MP320, BASF) with a solid content of more than $99 \%$ is used. Physical properties of these materials are shown in table (1). The nano-silica content for different cases was 2,4 , and $6 \mathrm{wt} \%$. In this study, a super plasticizer (SP) of carboxylic ether (Glenium-110P, BASF) with specific gravity $1.1 \mathrm{gr} / \mathrm{cm} 3$ (at $20^{\circ} \mathrm{C}$ ) and three types of reinforcing fibers namely polypropylene (PP fibers, peypolsazan),stainless steel (DUOLOC 36/0.8, BASF) and glass(Chopped Strand, bloorintar) (See Fig.(1) and Table (2) ) were used.

Table (1): Properties of nano-Silica.

\begin{tabular}{llll}
\hline $\begin{array}{l}\text { Diameter } \\
(\mathbf{n m})\end{array}$ & $\begin{array}{l}\text { Surface- volume } \\
\text { ratio }(\mathbf{m} \mathbf{2} / \mathbf{g})\end{array}$ & $\begin{array}{l}\text { Density } \\
(\mathrm{g} / \mathbf{c m} \mathbf{)})\end{array}$ & $\begin{array}{l}\text { Purity } \\
(\mathbf{\%})\end{array}$ \\
\hline $15 \pm 5$ & $160 \pm 20$ & $<0.15$ & $>99.9$ \\
\hline
\end{tabular}

Table (2):Properties of the reinforcing fibers.

\begin{tabular}{ccccccc}
\hline Type & $\begin{array}{c}\text { Length } \\
(\mathbf{m m})\end{array}$ & $\begin{array}{c}\text { diameter } \\
(\mathbf{m m})\end{array}$ & $\begin{array}{c}\text { Tensile strength } \\
(\mathbf{M P a})\end{array}$ & $\begin{array}{c}\text { Aspect } \\
\text { ratio } \\
\mathbf{l} / \boldsymbol{d}\end{array}$ & $\begin{array}{c}\text { Elastic modulus } \\
(\mathbf{G P a})\end{array}$ & $\begin{array}{c}\text { Density } \\
\left(\mathbf{g} / \mathbf{c m}^{3}\right)\end{array}$ \\
\hline Steel & 36 & 0.7 & 2100 & 50 & 160 & 7.8 \\
polypropylene & 12 & 0.1 & 450 & 120 & 5 & 0.9 \\
Glass & 12 & 0.1 & 1400 & 600 & 87 & 2.65 \\
\hline
\end{tabular}

Latin American Journal of Solids and Structures 11 (2014) 966-979 

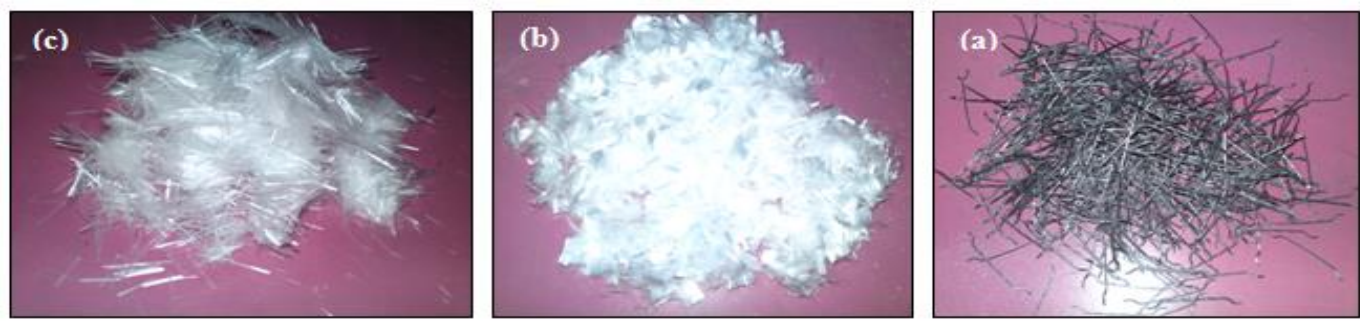

Fig. (1): Different types of fibers used in this investigation: (a) steel, (b) polypropylene, (c) Glass.

The size of gravel was less than $12.5 \mathrm{~mm}$ and in accordance with ASTM standard of grading curve. The sand was selected from sieve No. $4.75 \mathrm{~mm}$ equivalent to 76-percent sand. Cement was of Portland type II and specific gravity of limestone powder was $2.6 \mathrm{gr} / \mathrm{cm} 3$.

In the present work seventy mixtures in $\mathrm{A}, \mathrm{B}, \mathrm{C}$ and $\mathrm{D}$ categories representing $0,2,4$ and 6 percent of nano-silica particles replacing cement content were cast. Each series involves three different fiber type and content; $0.2,0.3$ and $0.5 \%$ volume for steel fiber, $0.1,0.15$ and $0.2 \%$ of volume for PP fiber and finally $0.15,0.2$ and $0.3 \%$ of volume for glass fiber. In all 40 samples, all variables were the same except for the fiber type and contents of fibers and nano-silica. The sample with Water/cement (nano-silica + cement) ratio of 0.39 and the sample with no fibers and nano-silica were considered as the control sample (Vf in Table (3) is the volume percent of fiber, i.e. fiber to concrete volume ratio).

\subsection{Curing and maintaining the samples}

Once the mixing process was completed, the samples were placed into molds and kept under laboratory condition for 24 hours. They were then removed from the molds and kept in $22-25^{\circ} \mathrm{C}$ water until the suitable age (28 days) for each experiment. Each mixing design included three $100 \times 100 \times 500 \mathrm{~mm}$ beam molds and three $100 \times 100 \times 840 \mathrm{~mm}$ beam molds. There were a total of 240 samples for 40 mix design protocols.

\section{3 experimental setup}

Flexural strength test was performed on a hydraulic Universal Testing Machine (UTM) equipped with displacement speed Control mechanism (displacement rate of $0.5 \mathrm{~mm} / \mathrm{min}$ ) according to the standard ASTM C1018-94b. The samples were $100 \times 100 \times 500 \mathrm{~mm}$ prismatic mixes. The distance between the two supports was $40 \mathrm{~cm}$. The results are presented in Table (3).

\section{Artificial neural networks (ANN):}

\subsection{Modeling using MLP-type neural networks}

Unknown function approximation has attracted a great deal of research from different areas such as statistic, data mining, and engineering sciences. Among various types of function approximation tools, artificial neural networks provide a framework which can learn or approximate any function from given data samples through a training process. One of the most important features of a neural network is its flexibility and ability to learn complicated relationships based on the data. Various neural network architectures exist, of which the most popular is the feedforward multi-layer perceptron (MLP). An MLP type of neural network consists of one input layer; one or more hidden layer(s) and one output layer with a large number of inter connected neurons. Fig. (2) shows the basic structure of a typical MLP network.

Latin American Journal of Solids and Structures 11 (2014) 966-979 
Table (3):Physical properties of the hardened concrete (28days)

\begin{tabular}{|c|c|c|c|c|c|c|c|c|c|c|c|}
\hline $\begin{array}{l}\text { Nano } \\
\text { Silica } \\
(\%) \\
\end{array}$ & $\begin{array}{l}\text { Fib } \\
\text { VF }\end{array}$ & & $\begin{array}{c}\text { Flexural } \\
\text { strength } \\
\text { (Mpa) }\end{array}$ & $\begin{array}{l}\text { Toughness } \\
\text { (N.mm) }\end{array}$ & $\begin{array}{c}\mathrm{GF} \\
(\mathrm{J} / \mathrm{m} 2)\end{array}$ & $\begin{array}{c}\text { Nano } \\
\text { Silica } \\
(\%)\end{array}$ & $\begin{array}{l}\text { Fil } \\
\text { VF }\end{array}$ & & $\begin{array}{c}\text { Flexural } \\
\text { strength } \\
\text { (Mpa) }\end{array}$ & $\begin{array}{l}\text { Toughness } \\
\text { (N.mm) }\end{array}$ & $\begin{array}{c}\text { GF } \\
(\mathrm{J} / \mathrm{m} 2)\end{array}$ \\
\hline \multirow{10}{*}{0} & \multicolumn{2}{|c|}{-} & 5.16 & 1190 & 143.5 & & \multicolumn{2}{|c|}{-} & 7.2 & - & - \\
\hline & \multirow{3}{*}{ St } & 0.2 & 6.02 & 20651 & 2653 & & \multirow{3}{*}{ St } & 0.2 & 8.4 & 22505 & 2871.1 \\
\hline & & 0.3 & 6.58 & 22695 & 2893.5 & & & 0.3 & 8.6 & 26785 & 3374.7 \\
\hline & & 0.5 & 7.08 & 31169 & 3890.4 & & & 0.5 & 9.1 & 35105 & 4353.5 \\
\hline & \multirow{3}{*}{ P.P } & 0.1 & 5.82 & 3843 & 529.7 & 4 & \multirow{3}{*}{ P.P } & 0.1 & 7.5 & 3980 & 545.8 \\
\hline & & 0.15 & 6.24 & 5012 & 667.3 & & & 0.15 & 7.8 & 5309 & 702.2 \\
\hline & & 0.2 & 6.6 & 5433 & 716.8 & & & 0.2 & 7.9 & 5911 & 773 \\
\hline & \multirow{3}{*}{ Glass } & 0.15 & 5.52 & 2314 & 285.2 & & \multirow{3}{*}{ Glass } & 0.15 & 8.5 & 2470 & 303.5 \\
\hline & & 0.2 & 8.1 & 3001 & 366 & & & 0.2 & 9 & 3102 & 377.8 \\
\hline & & 0.3 & 7.8 & 2570 & 315.3 & & & 0.3 & 8.7 & 2515 & $\begin{array}{r}308.8 \\
\end{array}$ \\
\hline \multirow{10}{*}{2} & \multicolumn{2}{|c|}{-} & 5.52 & - & - & & \multicolumn{2}{|c|}{-} & 7.2 & - & - \\
\hline & \multirow{3}{*}{ St } & 0.2 & 7.2 & 23748 & 3017.4 & & \multirow{3}{*}{ St } & 0.2 & 8.3 & 21078 & 2703.3 \\
\hline & & 0.3 & 7.53 & 27553 & 3465 & & & 0.3 & 8.6 & 21970 & 2808.2 \\
\hline & & 0.5 & 7.4 & 36468 & 4513.8 & & & 0.5 & 9 & 30556 & 3818.5 \\
\hline & \multirow{3}{*}{ P.P } & 0.1 & 6.1 & 4343 & 588.6 & 6 & \multirow{3}{*}{ P.P } & 0.1 & 7.2 & 3850 & 530.6 \\
\hline & & 0.15 & 6.4 & 5357 & 707.8 & 0 & & 0.15 & 7.8 & 5112 & 679 \\
\hline & & 0.2 & 7 & 6007 & 784.3 & & & 0.2 & 7.8 & 5430 & 716.5 \\
\hline & \multirow{3}{*}{ Glass } & 0.15 & 6.7 & 2503 & 307.4 & & \multirow{3}{*}{ Glass } & 0.15 & 8.2 & 2270 & 280 \\
\hline & & 0.2 & 8.3 & 3177 & 386.7 & & & 0.2 & 8.8 & 2876 & 351.3 \\
\hline & & 0.3 & 8.1 & 2693 & 329.8 & & & 0.3 & 8.6 & 2482 & 304.9 \\
\hline
\end{tabular}

An example of a MLP type of neural network with one input node, a single hidden layer with two neuron and one output neuron is shown in Fig.(3). An additional input called bias with constant value of 1 is added to the previous input node which works as a shift operator. Each input node is related to each neuron in hidden layer by a connecting weight. The sum of the products of the weights and the inputs is calculated by each neuron in hidden layer and then treated by an activation function. The obtained result is then multiplied by the associated weight $C_{3}$ and again the previous procedure will be repeated in the output neuron. In the present study hyperbolic tangent and linear functions are used as the activation functions in the hidden and output layers respectively.

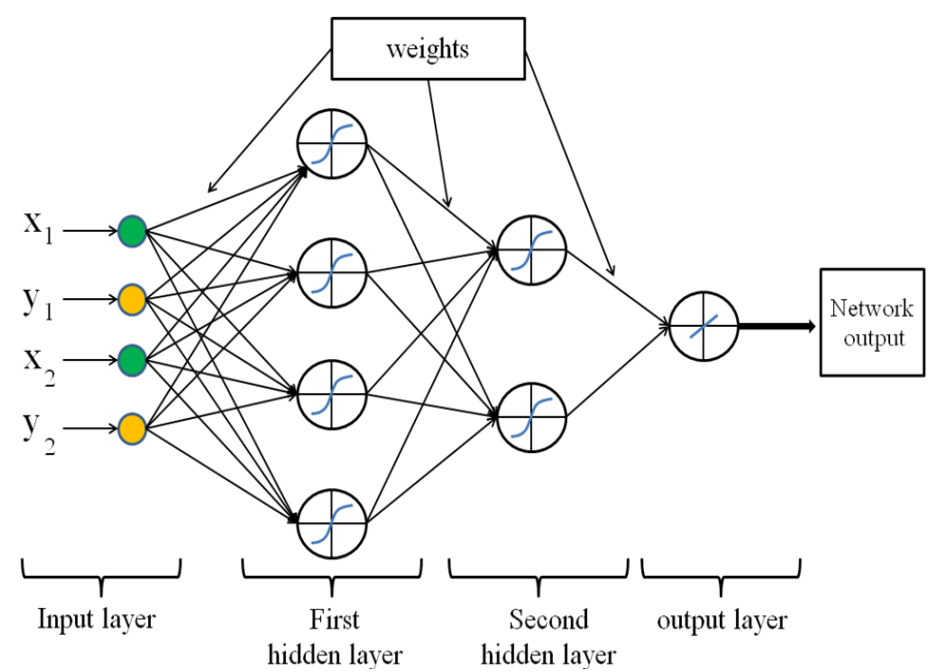

Fig.(2): The structure of an MLP-type network. 


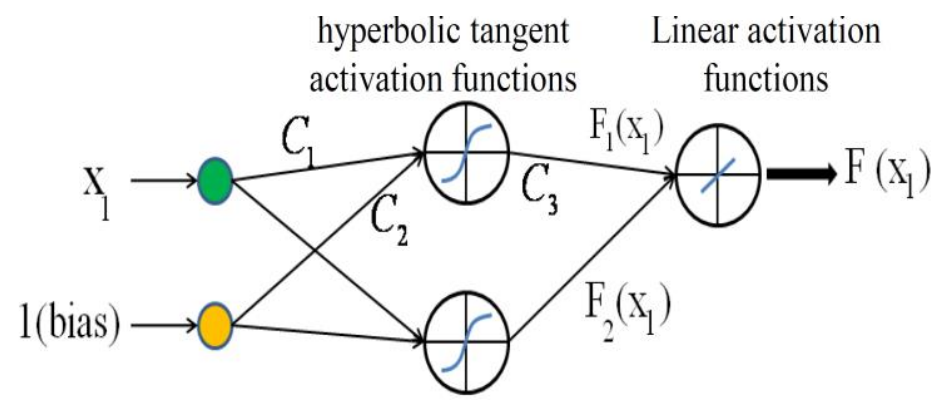

Fig. (3): Architecture of a network with one hidden layer containing two neurons and one neuron in the output layer.

The final output of the current network is calculated as

$$
\operatorname{Network~output}(N O)=F_{1}\left(x_{1}\right)+F_{2}\left(x_{1}\right)=F\left(x_{1}\right)
$$

where,

$$
F_{1}\left(x_{1}\right)=C_{3} \tanh \left(C_{1} x_{1}+C_{2}\right)
$$

Once the number of layers and the number of neurons in each layer, have been selected, the network's weights must be adjusted to minimize the prediction error made by the network. This is the general role of the training algorithms. In this investigation Back-propagation (BP) method is applied to train the ANN which is the most widely used learning process in neural networks today.

\subsection{Back-Propagation algorithm}

Back-propagation was firstly proposed by Werbos (Werbos, 1974) which is based on searching an error surface (error as a function of ANN weights) using the gradient descent algorithm for points with minimum error.

Consider a network with one hidden layer and one output neuron as shown in Fig (4).

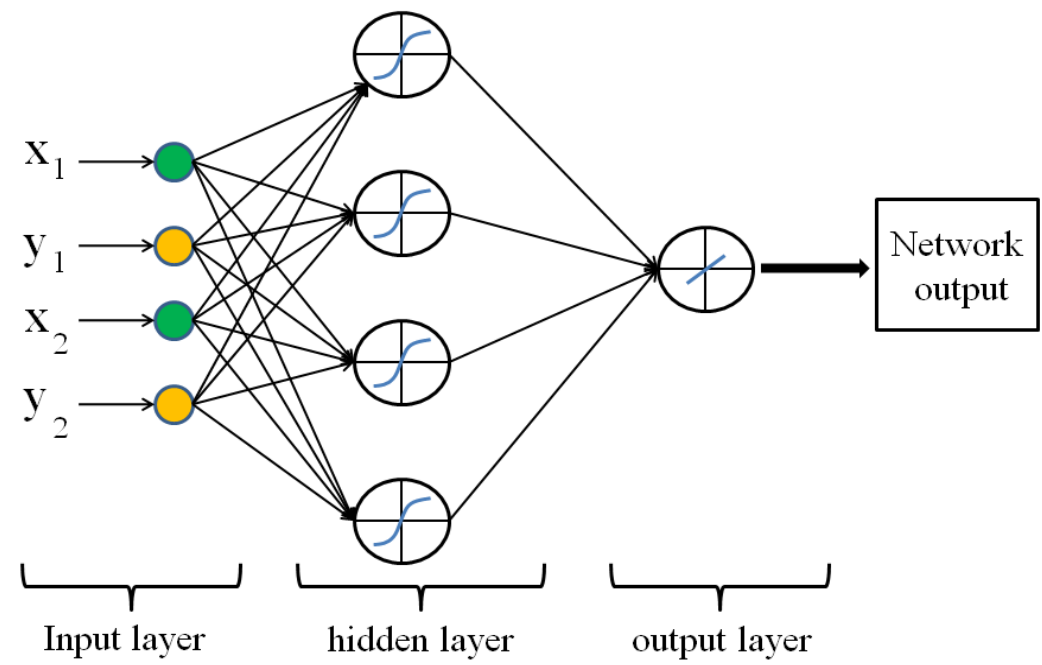

Fig. (4): A feed-forward multi-layer perceptron type of neural network with one hidden layer.

When a set of input data (input vector) are propagated through the network, for the current set of weights there is an output Est. The training of perceptron is a supervised learning algorithm 
where weights are adjusted to minimize the absolute error between the estimated output Est of network and the desired output Des whenever the estimated output does not match the desired output. If the network error $(N E)$ is defined as:

$$
\text { Network Error }=\text { Est }- \text { Des }=N E
$$

The training algorithm should adjust the weights to minimize $N E^{2}$. For this purpose an artificial neuron with its basic elements is considered as shown in Fig .(5). The neuron consists of three basic components; weights, a summing junction and an activation function.

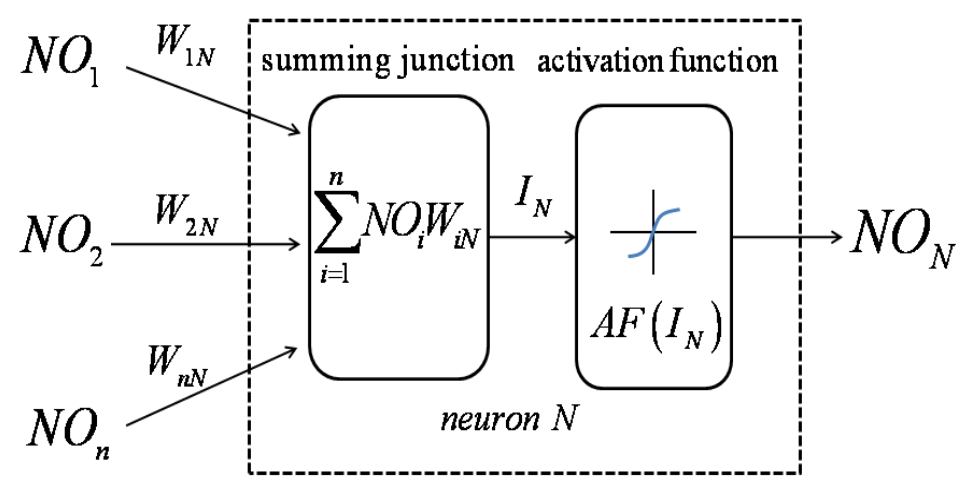

Fig. (5): Basic elements of an artificial neuron

The outputs of $n$ neurons $N O_{1}, \ldots, N O_{n}$ lead in neuron $N$ as the inputs. If neuron $N$ is in the hidden layer then this is the input vector of the network. These outputs are multiplied by the associated weights $W_{1 N}, \ldots, W_{n N}$. The summing junction adds together all these products to provide the input $I_{N}$ for activation function of neuron $N$. Then $I_{N}$ passes through the activation function $A F\left(\right.$ ) and gives the final output of neuron $N$, which is $N O_{N}$.

To commence the calculations, consider neuron $M$ and weight $W_{M N}$ which connects the two neurons. The equation for weight update is as follows

$$
W_{M N(\text { adjusted })}=W_{M N(\text { old })}-L R \cdot \frac{\partial\left(N E^{2}\right)}{\partial W_{M N}}
$$

where $L R$ is the learning rate parameter and $\partial(N E)^{2} / \partial W_{M N}$ is error gradient with reference to the weight $W_{M N}$. The chain rule gives

$$
\frac{\partial\left(N E^{2}\right)}{\partial W_{M N}}=\frac{\partial\left(N E^{2}\right)}{\partial I_{N}} \frac{\partial I_{N}}{\partial W_{M N}}
$$

since the rest of the inputs to neuron $N$ are independent of the weight $W_{M N}$ we have

$$
\frac{\partial I_{N}}{\partial W_{M N}}=\frac{\partial \sum_{i=1}^{n} N O_{i} W_{i N}}{\partial W_{M N}}=\frac{\partial N O_{M} W_{M N}}{\partial W_{M N}}+\frac{\partial \sum_{i=2}^{n} N O_{i} W_{i N}}{\partial W_{M N}}=N O_{M}
$$

Eqs. (4), (5) and (6) give

$$
W_{M N(\text { adjusted })}=W_{M N(\text { old })}-L R \cdot \frac{\partial\left(N E^{2}\right)}{\partial I_{N}} N O_{M}
$$

For the case $N$ is an output neuron we have: 


$$
\begin{aligned}
& \partial\left(N E^{2}\right)=\partial(E s t-D e s)^{2} \longrightarrow \\
& \frac{\partial\left(N E^{2}\right)}{\partial I_{N}}=2(E s t-D e s) \frac{\partial E s t}{\partial I_{N}}=2(N E) \frac{\partial A F\left(I_{N}\right)}{\partial I_{N}}=2(N E) \times A F^{\prime}\left(I_{N}\right)
\end{aligned}
$$

Substituting Eq. (8) into Eq. (7) gives

$$
W_{M N(\text { adjusted })}=W_{M N(\text { old })}-L R \cdot N O_{M} \cdot 2(N E) \times A F^{\prime}\left(I_{N}\right)
$$

For hyperbolic tangent and linear activation functions $A F^{\prime}\left(I_{N}\right)$ and the final form of weight update rule can be written as follows

For hyperbolic tangent: $\left\{\begin{array}{l}A F^{\prime}\left(I_{N}\right)=1-\left[A F\left(I_{N}\right)\right]^{2} \longrightarrow \\ W_{M N(\text { adjusted })}=W_{M N(\text { old })}-L R \cdot N O_{M} \cdot 2(N E) \times\left(1-\left[A F\left(I_{N}\right)\right]^{2}\right)\end{array}\right.$

$$
\text { for linear functions: }\left\{\begin{array}{l}
A F^{\prime}\left(I_{N}\right)=1 \\
W_{M N(\text { adjusted })}=W_{M N(\text { old })}-L R \cdot N O_{M} \cdot 2(N E)
\end{array}\right.
$$

When $N$ is a hidden layer neuron

$$
\frac{\partial(N E)^{2}}{\partial I_{N}}=\frac{\partial\left(N E^{2}\right)}{\partial I_{o n}} \frac{\partial I_{o n}}{\partial N O_{N}} \frac{\partial N O_{N}}{\partial I_{N}}
$$

where the subscript on represents the output neuron. In Eq. (12) we have

$$
\begin{aligned}
\frac{\partial N O_{N}}{\partial I_{N}}= & \frac{\partial A F\left(I_{N}\right)}{\partial I_{N}}=A F^{\prime}\left(I_{N}\right), \\
\frac{\partial I_{o n}}{\partial N O_{N}} & =\frac{\partial \sum_{i} N O_{i} W_{i o n}}{\partial N O_{N}}=\frac{\partial N O_{N} W_{N o n}}{\partial N O_{N}}+\frac{\partial \sum_{i}^{i \neq N} N O_{i} W_{i o n}}{\partial N O_{N}}=W_{N o n}
\end{aligned}
$$

substituting Eq. (13) into Eq. (12) gives

$$
\frac{\partial\left(N E^{2}\right)}{\partial I_{N}}=\frac{\partial\left(N E^{2}\right)}{\partial I_{o n}} W_{N \text { on }} \times A F\left(I_{N}\right)
$$

In Eq. (14), $\partial\left(N E^{2}\right) / \partial I_{N}$ is now written as a function of $\partial\left(N E^{2}\right) / \partial I_{o n}$ which was calculated in Eq. (8).

Hence the weight update rule for a hidden layer neuron takes the following form

$$
W_{M N(\text { adjusted })}=W_{M N(\text { old })}-L R \cdot N O_{M} \frac{\partial\left(N E^{2}\right)}{\partial I_{o n}} W_{N \text { on }} \times A F\left(I_{N}\right)
$$

\subsection{Performance of neural network}

The most common parameters for evaluation of a neural network's performance are minimum total squared errors (or RMS error) and minimum total absolute error (DTI, 1994) (or MAE error). MAE and RMS errors are defined as

$$
\text { RMS error: } \sqrt{\frac{\sum_{i=1}^{n}\left(\text { Des }_{i}-E s t_{i}\right)^{2}}{n}}
$$


MAE error: $\frac{\sum_{i=1}^{n}\left|D e s_{i}-E s t_{i}\right|}{n}$

where $n$ is the number of training data. The number of hidden layers and the neurons in each of them should be determined in a way to minimum the above errors.

\section{Results and discussion}

\subsection{Modeling of output using MLP-type neural network}

The input-output data pairs used in the present work consist of two input variables, namely the nano-silica and fiber percents and three output toughness, fracture energy and flexural strength obtained from experimental test. Before training procedure the data set was normalized to their mean value and standard deviation 1 . A training set of 14 out of 16 input-output data pairs is used to train the MLP-type neural network with only one hidden layer based on BP algorithm for each fiber. The remaining 2 data pairs are used to test the network performance. Since there are two input variables the network has two neurons in the input layer and one neuron in the output layer. Hence there is no specific method to determine the number of neurons in the hidden layer, Trial and error was used. Fig.(6) depicts the effect of different neural network architecture (different number of neurons in the hidden layer) on the RMS error of the network obtained from the normalized data. As can be seen a network with 12 neurons in the hidden layer has an acceptable performance.

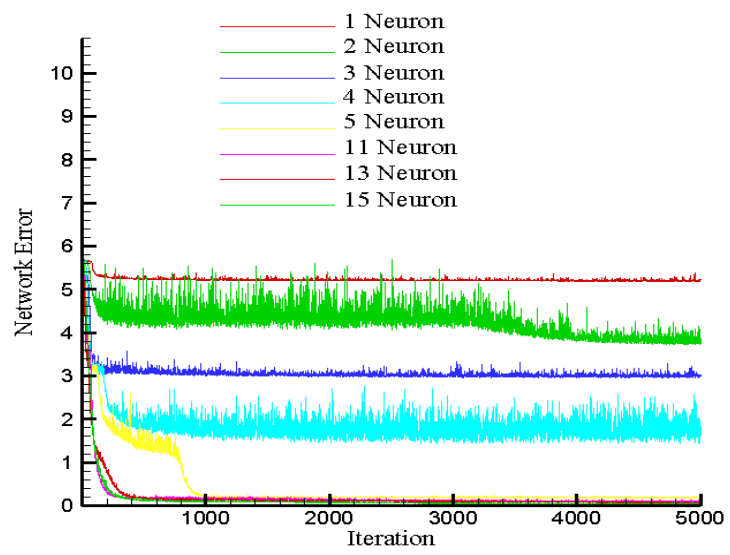

Fig.(6): effects of the number of hidden neurons on the network performance for PP fiber and nano-silica particles.

The excellent behavior of the MLP-type neural network for both training and testing data for the present case is also shown in Fig. (7). The figure reveals that the trained network is able to model and predict the outputs successfully.

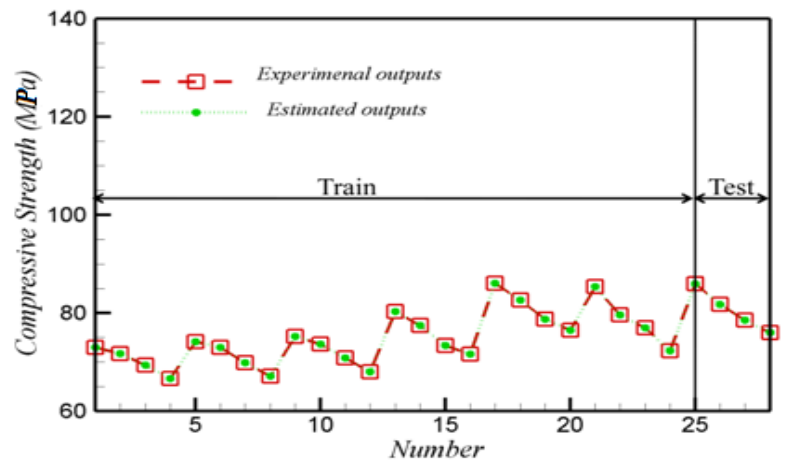

Fig. (7): Performance evaluation of the neural network in prediction of $\mathrm{G}_{\mathrm{F}}$ for $\mathrm{PP}$ and nano-silica particles 


\subsection{Flexural strength}

Figure (8) shows a direct relationship between the flexural strength and content of reinforcing fibers (steel, polypropylene and glass). Maximum increase in flexural strength equals 7.08, 6.6 and 8.1 $\mathrm{MPa}$ when there is an increase of $0.5 \mathrm{v} \%$ in steel, $0.2 \mathrm{v} \%$ in polypropylene and $0.2 \mathrm{v} \%$ in glass fibers, respectively. The percentages of these increases, compared with the reference sample (A1) are 37, 28 and 56 percent, respectively. As it can be seen from Figure (8), in the samples without fibers, increase of nanosilica content up to 5 percent increased the flexural strength continuously in a linear manner to a peak at $5 \mathrm{wt} \%$ of nanosilica (optimum percentage). Any further increase in nanosilica content caused no increase in flexural strength. On the other hand tensile strength behavior of the samples shows that higher amount of nanosilica contents increase the reinforcing fibers-induced flexural strength increases more significantly. For instance, an increase of $5 \mathrm{wt} \%$ nanosilica in the mixes containing the highest content of fibers $(0.3 \%$ steel fiber, $0.2 \%$ polypropylene fiber and $0.2 \%$ glass fiber), increased the flexural strength as much as 76, 53 and 75 percent, respectively, compared with the reference sample. Flexural strength assessments demonstrated that having filler and pozzolanic effects, nanosilica can improve the structural properties and adhesive of the cement matrixfibers and mortar-aggregates interfaces area.

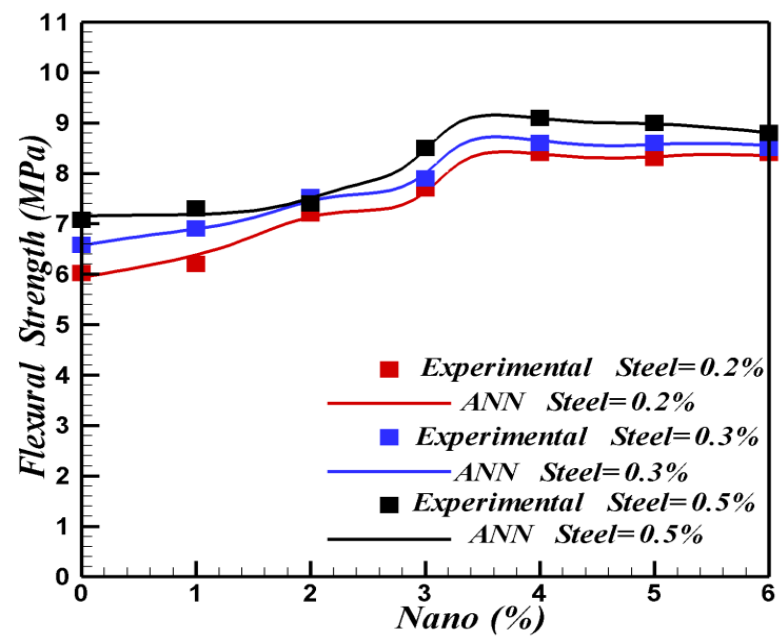

a) ST fibers.

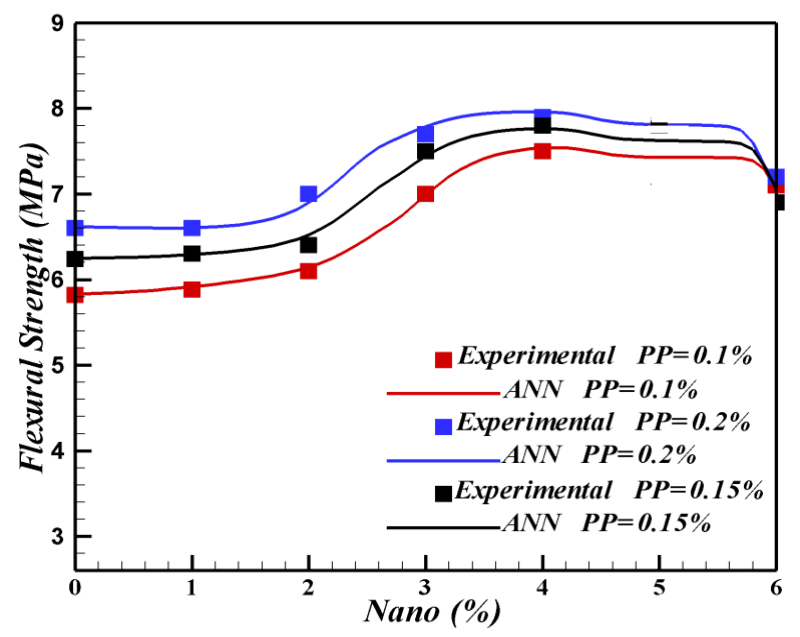

b) P.P fibers.

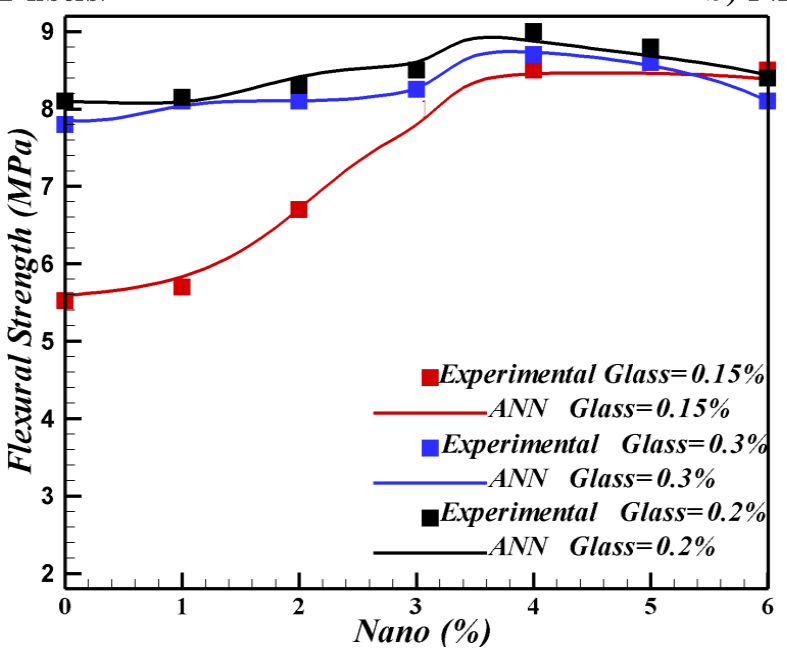

c) Glass fibers.

Fig. 8: Flexural strength of the samples containing: a) ST fibers; b) P.P fibers; c) Glass fibers

Latin American Journal of Solids and Structures 11 (2014) 966-979 


\subsection{Toughness}

The main important role of adding reinforcing fibers to concrete is making links between cracks produced by different causes. If the fibers in volume unit have enough density, strength and are well ad hered to cement matrix, they can limit the spread of cracks and give the fiber-reinforced concrete efficient tolerance against greater stresses after the appearance of cracks. This also improves the formability of concrete after the appearance of cracks. This formability is called toughness.

Fig. (9) show that increasing the percentage of fibers increases toughness. Steel, polypropylene and glass fibers can increase toughness in fiber-reinforced concretes up to $20-30,5$ and about 3 times, respectively. Obviously metal fibers play more crucial role in boosting toughness. When 3 wt\% of nanosilica is added to the mixture, the fiber-induced toughness is also increased. Increasing the percentage of nanosilica to more than $3 \mathrm{wt} \%$, decreased the toughness. This decrease was because of high values of pull-out strength of fibers in stronger matrixes which was in turn because of the presence of strong cement matrix-fibers bonds. This characteristic can lead to a brittle rupture without being pulled out of the matrix. But in mixtures of series B, containing $2 \mathrm{wt} \%$ of nanosilica, pull-out strength between fibers and matrix is so much that delays pulling-out mechanism and causes the fiber concrete to absorb more energy. Therefore, $3 \mathrm{wt} \%$ of nanosilica can be considered as optimal percentage for the toughness of the mixing designs.

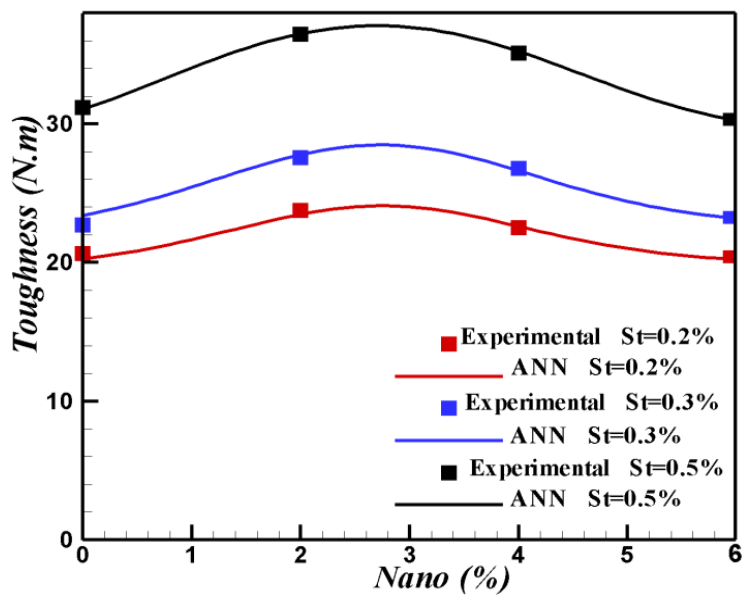

a) ST fibers

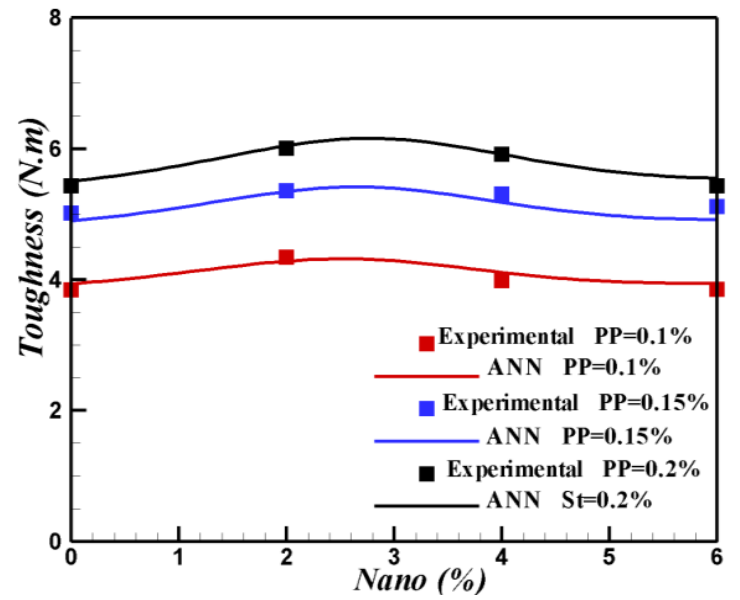

b) P.P fibers

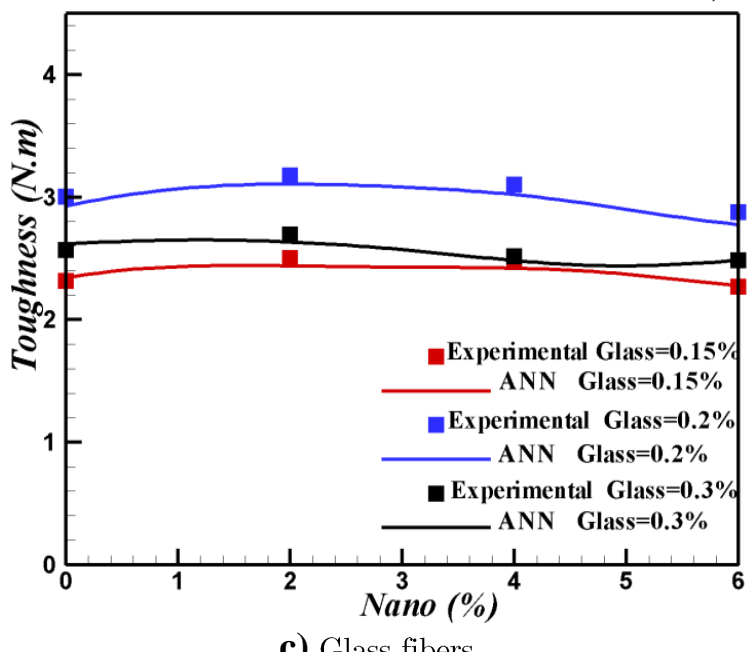

Fig. 9: Toughness of samples with different fibers: a) ST fibers; b) P.P fibers; c) Glass fibers

Latin American Journal of Solids and Structures 11 (2014) 966-979 


\subsection{Fracture energy}

Fig. (10) indicates that increasing the percentage of fibers increases fracture energy. This behavior may be explained with the fact that descending branch of the curve load - displacement correlate to control specimen with increasing fiber percent, has met a significant softening strain that The behavior in the samples containing fibers, especially metal fibers significantly in form softer failure improved and has created more area under the curve of the load - displacement that mainly has been after the post peak and as the energy absorption capability of control concrete increases.

The figure also shows that with increase of nano-silica percentage the fracture energy increases at the beginning until an optimum nano-silica percentage (3 wt\%) and after that it decreases again.

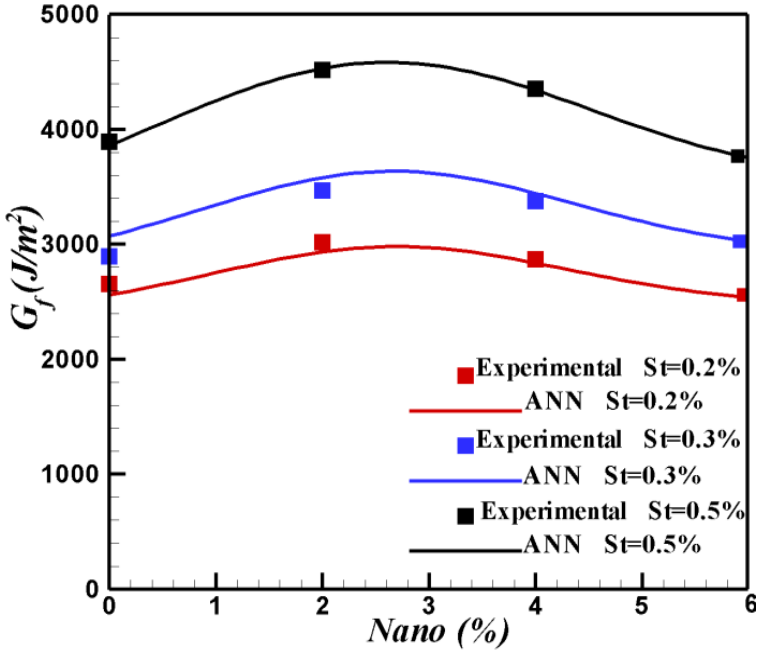

a) ST fibers

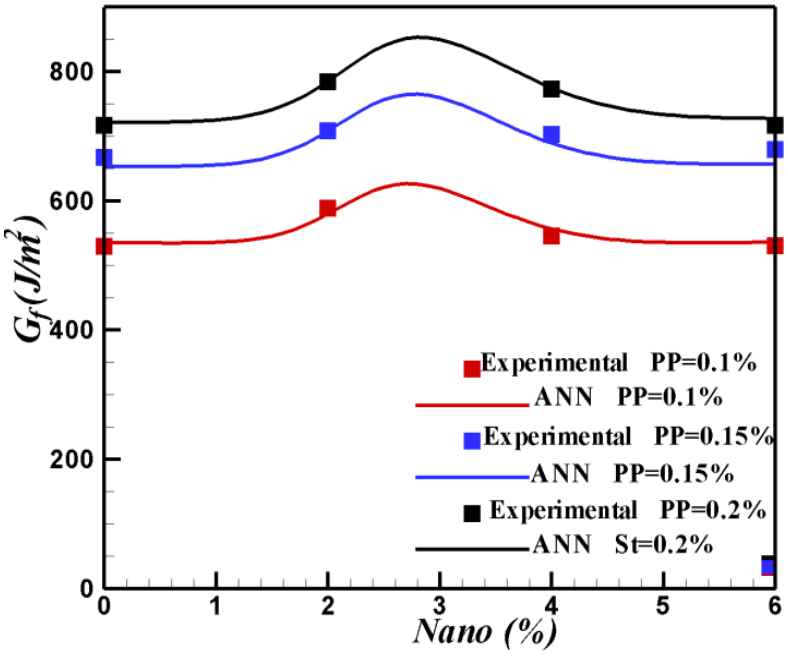

b) P.P fibers

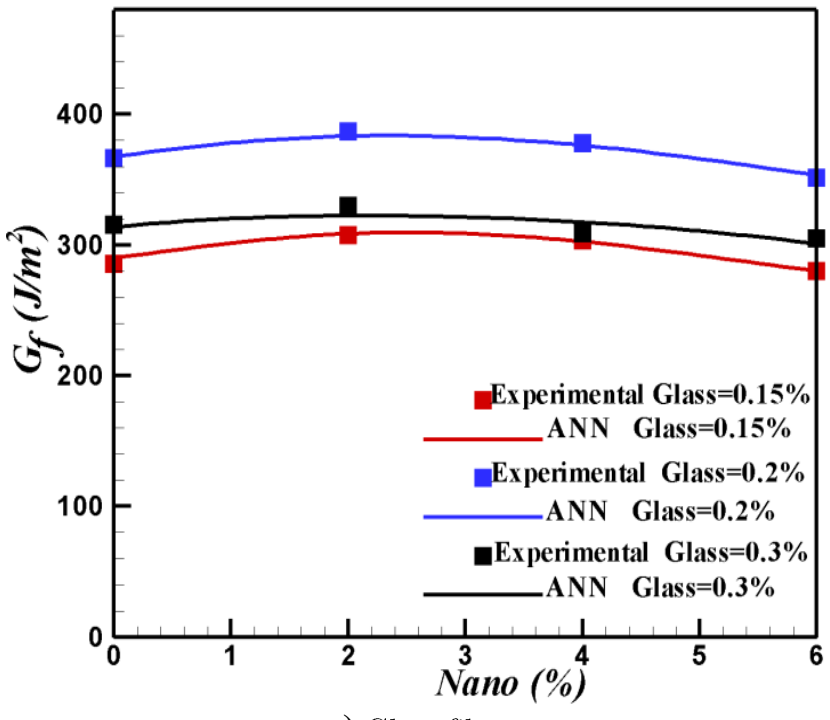

c) Glass fibers

Fig. 10: GF of samples with different fibers: a) ST fibers; b) P.P fibers; c) Glass fibers. 


\section{CONCLUSIONS}

In this paper a neural network model was used to estimate the combined effects of fibers and Nano silica on the on the toughness, flexural strength and fracture energy of Self- Compacting Concrete. From this investigation, some conclusions were summarized as follows:

In order to predict the toughness, flexural strength and fracture energy, models were constructed by MLP-ANN method.

Comparison shows that the obtained ANN results have good agreement with the experimental results

Findings of the flexural assessments among the mixtures showed that increasing the content of fibers, especially metal fiber, increases flexural strengths and therefore, the consequent formability is significantly increased. Additionally, increasing nano-silica content to $5 \mathrm{wt} \%$, increases the tensile and flexural strengths more significantly which is because of the filling and pozzolanic effects of nano-silica in contact area between fibers and cement matrix.

Evaluating the results of toughness assessments in different mixing designs showed that increasing the fibers contents significantly increased the toughness of concrete. Steel, polypropylene and glass fibers can boost toughness in fiber concrete up to $20-30,5$ and about 3 times, respectively. It shows that steel fibers have better performance with relation to energy absorption capacity.

Increasing nanosilica content up to $3 \mathrm{wt} \%$, increased the toughness of the samples significantly. However, further increase more than $3 \mathrm{wt} \%$, decreased toughness. This reduction is because of a highly pull-out strength of fibers in stronger matrixes which in turn is because of the presence of a strong cement matrix-fibers bond. This strong bond can lead to a brittle rupture without removal of fibers from the matrix.

\section{References}

ACI 544, (1988), "Measurement of Properties of Fiber Reinforced Concrete", American Concrete Institute, 85(6), 583-93.

AENOR, (1989), "Detemination of the Toughness Index and First Crack Strength", Asociation Espanola de Normalisacion y Certification, 28010, 4. Pp.

Arslan MH. Application of ANN to evaluate effective parameters affecting failure load and displacement of RC buildings. Nat Hazards Earth Syst Sci J 2009;9:967-77

Arslan MH, Ceylan M, Kaltakcı MY, Ozbay Y, Gulay G. Prediction of force reduction factor R of prefabricated industrial buildings using neural networks. Struct Eng Mech 2007;27(2):117-34

Bazant, Z. P., Planas, J., "Fracture and Size Effect in Concrete and other Quasibrittle Materials", CRC Press, Florida, USA, 1997.

Bazant, Z. P., Kazemi, M. T., "Size Effect in Fracture of Ceramics and its Use to Determine Fracture Energy and Effective Process Zone Length", J. Am. Ceram. Soc., Vol. 73, No. 7, 1990, pp. 1841-1853.

DBV, (1992), "Basis for Dimensioning SFRC in Tunnel Construction", Deutschen Beton-Vereins, pp. $19-43$.

DTI, Best Practice Guidelines for Developing Neural Computing Applications, 1994.

Elices, M., Guinea, G. V., Gomez, J., and Planas, J., "The Cohesive Zone Model: Advantages, Limitations And Challenges", Engineering Fracture Mechanics, Vol. 69, 2002, pp. 137-163.

Flood I, Muszynski L, Nandy S. Rapid analysis of externally reinforced concrete beams using neural networks. Comput Struct 2001;79:1553-9.

Goh ATC. Prediction of ultimate shear strength of deep beams using neural networks. ACI Struct J 1995;92(1):2832.

Guang NH, Zong WJ. Prediction of compressive strength of concrete by neuralnetworks. Cem Concr Res 2000;30:1245-50.

Guo, X. H., Tin -Loi, F., and Li, H., "Determination of Quasi-Brittle Fracture Law for Cohesive Crack Models", Cement and Concrete Research, Vol. 29, 1999, pp. 1055-1059. 
Henegar, C.H., (1978), "Toughness Index of Fiber Concrete", Testing and Test Methods of Fiber Cement Composites. Construction Press Ltd, Lancaster, UK, pp. 79-86.

IBN, (1992), "Test of Reinforced Concrete .Bending Test on Prismatic Specimens", institute Belge de Normalisation, 1040 Brussels, Belgium, 9 pp.

Jamal A, Abdalla A, Elsanosi A. Abdelwahab. Modeling and simulation of shear resistance of R/C beams using artificial neural network. J Franklin Inst 2007;344:741-56.

JCI, (1984), " Method of Tests for Flexural Strength and Flexural Toughness of Fiber Reinforced Concrete", JCI Standard SF-4, Japan Concrete Institute Standards for Test Method of Fiber Reinforced Concrete, pp.45-51.

Jenq, Y. S., and Shah, S. P., "Two Parameter Fracture Model for Concrete", Journal of Engineering Mechanics, Vol. 111, No. 10, 1985, pp. 1227-1241.

Khayat KH, Workability testing and performance of Self-Consolidating Concrete. ACI Mater J, 96(3), (1999), pp. 346.

Navalurkar, R. K., Hsu, C. T. T., Kim, S. K., and Wecharanta, M., "True Fracture Energy of Concrete", ACI Materials Journal, Vol. 96, No. 2, March-April 1999, pp. 213-224.

Nehdi M, El-Chabib H, El-Naggar H. Cost-effective SCC for deep foundations. Concrete International, 25(3), (2003), pp. 95-103.

Ouchi M, Hibino M, Okamura H. Effect of super plasticizer on self-compact ability of fresh concrete, TRR 1574, (1996), pp 37-40.

Ozawa K, Maekawa K, Okamura H. Self-Compacting high-performance concrete, Collected Papers (University of Tokyo: Department of Civil Engineering), 34, (1996), pp. 135-149.

Perera R, Barchin M, Artega A, De Diego A. Prediction of the ultimate strength of reinforced concrete beams FRPstrengthened in shear using neural networks. Compos Part B Eng 2010;41:287-98.

Pannirselvam N, Raghunath PN, Suguna K. Neural network for performance of glass fibre reinforced polymer plated RC beams. Am J Eng Appl Sci 2008:183-8.

RILEM 49TFR, (1984), "Testing Methods for Fiber Reinforced Cemet-Based Composites", RILEM Draft Recommeddations, Materials and Structures, 17. Pp.441-56.

RILEM TC-50 FMC, Fracture Mechanics of Concrete, "Determination of the Fracture Energy of Mortars and Concrete by Means of 3PB Tests on Notched Beams", RILEM Recommendation, Materials and Structures, Vol. 18, No. 106, 1988, pp. 285-290.

Romualdi JP, Batson GB. Mechanics of crack arrest in concrete. Proc ASCE1963; 89 (EM 3), pp. 147-68.

Romualdi JP, Batson GB. Mechanics of crack arrest in concrete. Proc ASCE1963; 89 (EM 3), pp. 147-68.

Safiuddin .Md, J.S. West, K.A. Soudki. Flowing ability of the mortars formulated from self-compacting concretes incorporating rice husk ash. Construction and Building Materials, 25, (2011), pp. 973-978.

Sanad A, Saka MP. Prediction of ultimate shear strength of reinforced concrete deep beams using neural networks. J Struct Eng, ASCE 2001;127(7):818-28.

Seung Hun Park, Dong Joo Kim, Gum Sung Ryu, Kyung Taek Koh. Tensile behavior of Ultra High Performance Hybrid Fiber Reinforced Concrete, Cement \& Concrete Composites, 34, (2012), pp. 172-184.

Shah, S. P., Swartz, S. E., and Ouyang, C., "Fracture Mechanics of Concrete", John Wiley and Sons, New York, USA, 1995.

Soroushian p. Secondary reinforcement adding cellulose fibers, ACI, Concrete International, (1986), pp. 28-38.

The European Guideline for self compacting concrete specification, production and use. May 2005.

Werbos .P.J, Beyond regression: New Tools for Prediction and Analysis in the Behavioural Sciences, Ph.D. Thesis, Harvard University, 1974.

Yang KH, Ashour AF, Song JK, Lee ET. Neural network modelling for shear strength of reinforced concrete deep beams. Struct Build 2008;161(1):29-39. 